\title{
INDÚSTRIA DE CELULOSE, DESENVOLVIMENTO E USO DO SOLO NA MICRORREGIÃO PORTO SEGURO, BAHIA
}

\author{
Rivanna Maria Figueredo de Matos \\ Mestre em Desenvolvimento Regional e Meio Ambiente \\ Universidade Estadual de Santa Cruz Ilhéus - BA - Brasil \\ rivanna.fm@gmail.com https://orcid.org/0000-0003-3768-4752 \\ Mônica de Moura Pires \\ Doutora em Economia Rural \\ Universidade Estadual de Santa Cruz Ilhéus - BA - Brasil \\ monicapires2009@gmail.com http://orcid.org/0000-0001-9036-514X
}

\section{RESUMO}

O eucalipto de florestas plantadas é a principal matéria-prima para a produção de celulose no Brasil, se inserindo em um mercado altamente competitivo e relevante para a economia. A Bahia, por sua vez, possui importantes empresas do setor e áreas com silvicultura, concentradas na microrregião Porto Seguro. Nesse sentido, este estudo analisa a relação da indústria de celulose com a dinâmica do desenvolvimento local e as mudanças no uso e ocupação do solo. O estudo organiza-se em três etapas: na primeira, tem-se o panorama da indústria de celulose, a partir de dados secundários; na segunda, estima-se o Indicador de Desenvolvimento Regional Sustentável (Idrs) para os 417 municípios baianos a partir de dados econômicos, sociais e ambientais, para os anos censitários 1991 e 2010, destacando-se os 19 municípios que compõem a microrregião. Por fim, analisa-se o uso e a ocupação do solo, por meio da apresentação de mapas extraídos da plataforma de geoprocessamento Mapbiomas, para os anos de 1985 e 2018. Os resultados obtidos indicam que a indústria de celulose gerou impactos substanciais no uso e na cobertura do solo, com a expansão dos maciços florestais e uma dinâmica de desenvolvimento economicamente associada à indústria de celulose. A silvicultura revela-se como fator determinante da dimensão ambiental e as disparidades, observadas no âmbito social, sinalizam um processo de desenvolvimento que necessita ampliar a sustentabilidade no sentido de promover maior autonomia e melhor qualidade de vida à população local, aprimorando as medidas de política de acesso a serviços públicos básicos.

Palavras-chave: Celulose. Eucalipto. Indicador de desenvolvimento regional sustentável. Uso e cobertura do solo.

\section{CELLULOSE INDUSTRY, DEVELOPMENT AND LAND USE AT THE MICRO-REGION PORTO SEGURO, BAHIA}

\begin{abstract}
Eucalyptus from planted forests is the main raw material for pulp production in Brazil, entering a highly competitive and relevant market for the economy. Bahia has important companies in the sector and areas with forestry, concentrated in the Porto Seguro region. The present study analyzes the relation of the pulp industry on the dynamics of local development and changes in land use and occupation. The study is organized in three stages: first, there is the panorama of the pulp industry, based on bibliographic research and secondary data; second, the Regional Sustainable Development Indicator (Idrs) is estimated from economic, social and environmental data, in the 1991 and 2010 census years for the 417 municipalities in Bahia, highlighting the 19 that make up the micro-region of this study. Finally, the analysis of land use and occupation in the micro-region studied is presented using maps extracted from the Mapbiomas geoprocessing platform, for the years 1985 and 2018. The results indicate that the cellulose industry generated substantial impacts on land use and cover, with the expansion of forestry and the dynamics of development in the micro region economically conditioned to the cellulose industry. Forestry is a determining factor in the environmental dimension and the disparities observed in the social scope demonstrate a development process that needs to expand sustainability, in order to promote greater autonomy and better quality of life for the local population, improving policy measures for access to services basic audiences.
\end{abstract}

Key words: Cellulose. Eucalyptus. Land use and cover. Regional sustainable development indicator.

Data da submissão: $13 / 04 / 2020$

Data de aceite: $01 / 05 / 2020$ 


\section{INTRODUÇÃO}

O desenvolvimento constitui-se em uma temática amplamente discutida, abrangendo diferentes áreas de conhecimento. Sua conceituação, origens e formas de mensuração são discutidas tanto no âmbito global, quanto regional e local. Inicialmente associado ao crescimento econômico, nas últimas décadas o desenvolvimento passou a envolver aspectos subjetivos, desde a melhora na qualidade de vida e bem-estar da população, até a ampliação da liberdade humana pelo acesso a garantias e oportunidades (Lima, 2006; Bellingieri, 2017; SEN, 2007).

Assim, o desenvolvimento explicita não somente a geração de riqueza e investimentos, incluindo também um objetivo social implícito, decorrente de melhorias qualitativas do local. Ao mesmo tempo, considerando as singularidades na estrutura de cada sociedade, percebe-se que não há como definir um modelo de desenvolvimento genérico, sendo essencial considerar as características regionais e socioambientais (Furtado, 2004).

Nesse sentido, os estudos sobre desenvolvimento sustentável apresentam contribuições relevantes na avaliação e mensuração dos impactos socioambientais associados às atividades produtivas, tal como o Indicador de Desenvolvimento Regional Sustentável (Idrs). O Idrs permite identificar o grau de dinamismo de um local de acordo com critérios de desenvolvimento sustentável, incluindo como fatores as dimensões econômica, social e ambiental, sendo assim um útil instrumento na análise das transformações nas estruturas produtivas regionais (Rodrigues; Lima, 2013; Bianco, Lima; Morejon, 2016; Lima et al., 2011.

Além dos indicadores, a análise de uso e ocupação do solo também são relevantes na compreensão de mudanças nas estruturas produtivas, pois relacionam-se às atividades, decorrentes da modernização e da integração, cada vez maior, entre indústria e agricultura, condicionando assim a dinâmica urbana-rural (Graziano Neto, 1986).

Tal modernização se dá de maneira mais contundente em segmentos específicos, como é o caso da indústria de celulose, uma commodity largamente utilizada na fabricação de diversos bens de consumo. No Brasil, o eucalipto é a principal matéria-prima empregada pelo setor, que nas últimas décadas vem colocando o estado da Bahia em posição de destaque (Perpetua; Kröger; Thomaz Junior, 2017).

Atualmente, o Brasil destaca-se com alta produtividade, o que fez com que o país se consolidasse no segmento como maior exportador e maior produtor (segunda posição na produção de celulose) e levasse o setor a ocupar expressiva importância para a economia nacional. Nesse mercado, a posição da Bahia foi sendo solidificada desde a década de 1990, fazendo com que a participação em 2017 do estado atingisse 15\% do total nacional no beneficiamento da celulose proveniente de eucalipto (Associação da Indústria Brasileira de Árvores - IBÁ, 2018; Associação Baiana das Empresas de Base Florestal - Abaf, 2019).

A eucaliptocultura integrada à produção de celulose associa-se às modificações na dinâmica de uso e ocupação do solo, concentração de terras, crescimento populacional urbano e intensificação do êxodo rural. Apesar de estimular a atividade econômica, contrapõe-se a importância do setor na promoção do desenvolvimento regional, a exemplo do extremo sul da Bahia, onde a inserção da indústria de celulose não representou melhorias significativas na qualidade de vida e redução das desigualdades (Almeida, 2009).

A indústria de celulose relaciona-se diretamente a fatores ambientais, por sua dependência de recursos hídricos e boas condições de solo, clima e extensas áreas de cultivo para produção de madeira de eucalipto, principal matéria-prima utilizada, tanto no Brasil como na Bahia (Perpetua; Kröger; Thomaz Junior, 2017).

Além disso, a alocação de áreas para a silvicultura em detrimento de outras atividades gera novas relações entre os territórios e transformações socioambientais das áreas do entorno, que, mesmo não participando diretamente do setor de celulose, passam a atender uma demanda por bens e serviços, associadas às operações dessa indústria. Assim, discute-se também o desenvolvimento 
sustentável nessas regiões, considerando o apelo ambiental associado ao uso de um recurso renovável (Andrade; Oliveira, 2016).

Diante do exposto, busca-se compreender o setor de celulose e sua relação com o desenvolvimento regional, tomando-se como região de análise a microrregião Porto Seguro, a qual é a principal produtora de celulose do estado da Bahia. Especificamente, analisam-se as transformações no uso e na ocupação do solo a partir da inserção da indústria de celulose na área de estudo e os fatores condicionantes da dinâmica econômica, social e ambiental a partir da aplicação do IDRS.

\section{DESENVOLVIMENTO, USO DO SOLO E O SETOR DE CELULOSE}

Nas últimas décadas, as teorias do desenvolvimento passaram a seguir uma nova trajetória, contemplando além de fatores econômicos, também aqueles das esferas social e ambiental, principalmente a partir dos anos 1970 após as discussões ocorridas no evento conhecido como Clube de Roma, em 1968, no qual foi lançado o termo ecodesenvolvimento. Dessa maneira, às distintas formas de análise do desenvolvimento foi incorporada a ideia de sustentabilidade, que preconiza um processo de desenvolvimento em harmonia com o uso dos recursos naturais pela redução dos problemas sociais e ambientais. Tal processo possui caráter endógeno, pois a renda gerada em determinada região deveria permitir melhorias na qualidade de vida da população local (Alves; Lima, 2007).

Assim, para compreender o processo de desenvolvimento e sustentabilidade, é necessário estabelecer divisões espaciais, retratando a identidade regional ao individualizar os espaços geográficos de acordo com suas características socioeconômicas e naturais, como as microrregiões, que retratam as especificidades dos territórios e as estruturas produtivas ali presentes, revelando a configuração do espaço em nível local (IBGE, 1990).

Considerando que o meio ambiente sofre ações antrópicas, os processos de produção e padrões de consumo vigentes nas sociedades atuais são claramente insustentáveis. Assim, espera-se que as atividades econômicas ocorram seguindo uma política de desenvolvimento que limite os fatores de geração de impactos ambientais, simultaneamente à ampliação da disponibilidade dos recursos naturais no curto e longo prazo. Nesse sentido, setores produtivos, que utilizam fontes renováveis, podem ser associados à promoção do desenvolvimento regional e da sustentabilidade se o crescimento econômico provocado pela implantação de uma nova indústria for acompanhado de melhorias nos aspectos que envolvem a dimensão social e ambiental (Diegues, 1992; Amaral Filho, 2001; Veiga, 2010).

A despeito das múltiplas atividades econômicas que coexistem em cada território, associar o processo de desenvolvimento regional a um único setor presume a compreensão do perfil produtivo da região em questão, que pode ser obtida por meio da análise do uso e ocupação do solo. E daí estabelecer relações entre a presença da agroindústria de celulose com a dinâmica econômica, ambiental e social regional, considerando que o setor utiliza extensas áreas para o cultivo de eucalipto.

Dada a consolidação indústria de celulose no Brasil nas últimas décadas, o seu potencial, como transformadora da dinâmica produtiva regional, tem sido tratado na literatura com cada vez mais frequência. No estado do Maranhão, por exemplo, que, com o início das operações de uma única unidade industrial em 2014, desponta como um dos principais produtores de eucalipto e celulose do país, já são verificadas transformações no espaço regional e urbano associados à atuação do setor (Oliveira; Pereira; Nascimento, 2018; Suzano, 2017).

$\mathrm{Na}$ literatura sobre o setor de celulose, seu padrão produtivo e de ocupação do solo e os seus desdobramentos para o desenvolvimento e sustentabilidade da microrregião baiana de Porto Seguro, destaca-se o diagnóstico das transformações socioeconômicas e mapeamento das modificações no uso da terra verificadas a partir do cultivo de eucalipto no Extremo Sul da Bahia em Almeida (2009) e Almeida et al, (2008). Já os trabalhos de Melina (2013), Perpetua; Kröger; Thomaz Junior

Revista de Gestão Social e Ambiental - RGSA, São Paulo, v. 14, n. 2, p. 65-81, maio/ago. 2020. 
(2017) e Perpetua; Thomaz Junior (2016) tratam do processo de especialização produtiva, concentração fundiária e questões socioambientais associadas à atuação do setor de celulose.

Por outro lado, a utilização do Indicador de Desenvolvimento Regional Sustentável (Idrs), proposto recentemente por Bianco, Lima e Morejon (2016) para avaliar o desenvolvimento na Região Sul do Brasil, é um instrumento de análise que possibilita quantificar a dinâmica de desenvolvimento que ainda não foi explorado em estudos sobre a atuação da indústria de celulose nas regiões, abrindo espaço para agregar uma nova discussão ao tema.

\section{METODOLOGIA}

A área de estudo deste trabalho engloba 19 municípios que compõem a microrregião geográfica Porto Seguro, Bahia, dentre as 32 microrregiões do estado da Bahia, de acordo com a classificação do Instituto Brasileiro de Geografia e Estatística (IBGE).

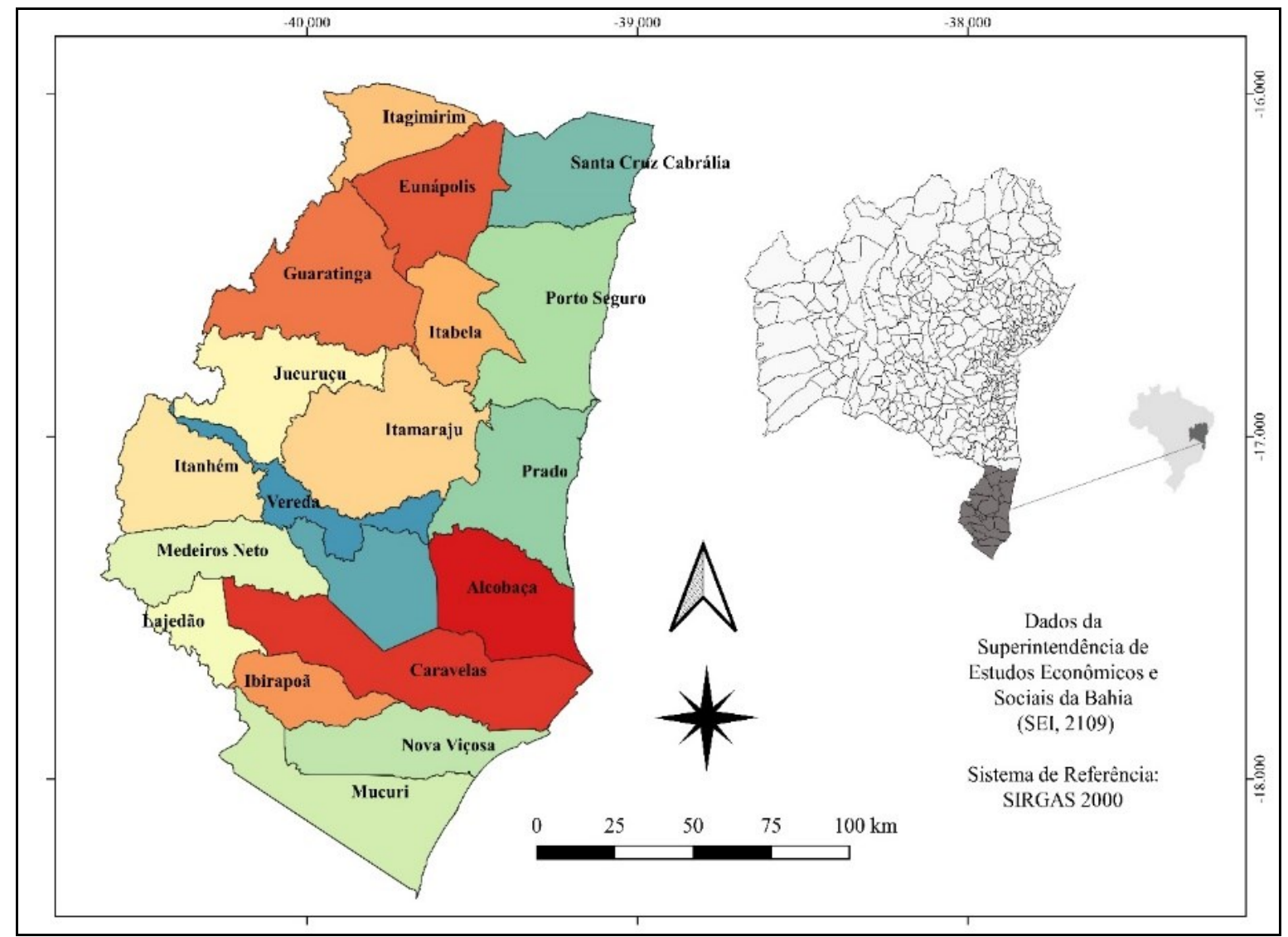

Figura 1 - Delimitação da área de estudo: microrregião Porto Seguro, Bahia

Fonte: Adaptado de "Mapas", da Superintendência de Estudos Econômicos e Sociais da Bahia (SEI), 2018.

$\mathrm{Na}$ área de estudo, o clima é predominantemente tropical chuvoso de floresta, úmido, com períodos de seca ao longo do ano, pluviosidade média anual de até $1500 \mathrm{~mm}$ e temperaturas acima de $18^{\circ}$. O relevo é caracterizado por planícies litorâneas, bacias sedimentares, planaltos costeiros e pré-litorâneos, predominância de solos do tipo argissolos e latossolos e vegetação natural do tipo floresta ombrófila densa, mata semidecidual e formações pioneiras de influência marinha e fluvial (SEI, 1983; 1998; 2001; 2004).

As fontes dos dados utilizados foram: Sistema Ibge de Recuperação Automática (Sidra), Superintendência de Estudos Econômicos e Sociais da Bahia (SEI), Instituto de Pesquisa Econômica Aplicada (Ipeadata, 2018), Programa das Nações Unidas para o Desenvolvimento (Pnud, 2018), Relação Anual de Informações Sociais (Rais, 2018) e Série Anual de Mapas da Cobertura e Uso do Solo do Brasil (MapBiomas). Também foram consultados sites institucionais 
das empresas de celulose da Bahia e associações do setor, além das plataformas do Ministério da Indústria Comércio Exterior e Serviços (Mdic, 2019) e da Organização das Nações Unidas para a Alimentação e a Agricultura (FAO), sobre produção e comércio exterior.

As análises foram feitas em três etapas: 1) Panorama da indústria de celulose, caracterizando o mercado em nível mundial e nacional, contextualizado a situação da microrregião Porto Seguro no setor; 2) Estimação do Idrs para os 417 municípios da Bahia, destacando os 19 que compõem a microrregião deste estudo e 3) Análise do uso e ocupação do solo na microrregião estudada por meio do uso de mapas.

No cálculo do Idrs foram considerados dois anos censitários 1991 e 2010, a fim de se observar transformações ao longo dessas décadas, pois a partir de 1991 ocorre a expansão e inserção de novos plantios de eucalipto nos municípios da região e instalação de empresas de celulose. $\mathrm{Na}$ análise de uso e ocupação do solo na microrregião Porto Seguro, foram elaborados mapas, buscando caracterizar as áreas com atividades produtivas, destacando aquelas com eucaliptocultura. A base de dados foi o MapBiomas para os anos 1985 e 2018.

O estudo apresenta algumas limitações: para o cálculo do Idrs, o segundo período considerado é o ano de 2010, devido ao elevado número de variáveis desagregadas em nível municipal utilizadas na estimação do indicador, com a maioria dos dados disponibilizados somente para os anos nos quais ocorrem os Censos do Ibge. Já para o MapBiomas, considerou-se a periodicidade com base na necessidade de se verificar mudanças substanciais, desde o período anterior à presença da indústria do setor (1985) até os dados mais recentes de uso e ocupação de solo na região (2018). No entanto, tais limitações podem representar futuras oportunidades para novos estudos, que atualizem o Idrs situando-o na mesma periodicidade das análises de uso do solo.

O Indicador de Desenvolvimento Regional Sustentável (Idrs) é estimado com base em indicadores parciais, definidos em três dimensões: econômica, ambiental e social. A determinação das variáveis e as equações utilizadas para compor os indicadores parciais do Idrs, foram extraídas de Bianco, Lima e Morejon (2016).

O Indicador Parcial Econômico (IEi) caracteriza-se por variáveis relacionadas à produção, arrecadação de impostos, renda e emprego nos municípios, sendo estimado conforme eq. 1:

$$
I E i=(I E F+I I C M S+I F P M+I D O T+I C E S+I R p C+I V A+I P S P+I D E F+I R O T) \times P
$$

Em que: $\mathrm{IEi}=$ Indicador Parcial Econômico; $\mathrm{IEF}=$ Índice do Emprego Formal do município i; Iicms = Índice do Icms do município i; Ifpm = Índice do Fundo de Participação do município i; Idot= Índice das Despesas Orçamentárias do município i; Ices= Índice do Consumo de Energia Setorial do município i; IRpc= Índice de Renda per capita no município i; IVA= Índice do Valor Adicionado do município i; Ipsp= Índice de Pessoas em Situação de Pobreza no município i; Idef= Índice de Desligamentos dos Empregos Formais no município i; Irot= Índice da Receita Orçamentária do município i; $\mathrm{P}=$ Participação da variável $\mathrm{W}$ do município i.

O Indicador Parcial Social (ISi) inclui aspectos relacionados ao acesso à serviços básicos pela população e fatores relacionados à urbanização, conforme descrito na eq. 2 :

$$
I S i=(I P U+I P R+I F E+I C E R+I D S S+I D A P+I D E C+I G+I M F+I D H M) \times P
$$

Em que: ISi = Indicador Parcial Social; IPU = Índice da População Urbana do município i; IPR = Índice da População Rural do município i; IFE = Índice da Taxa de Frequência do Ensino Fundamental do município i; Icer = Índice de Consumo de Energia Elétrica Residencial do município i; Idss = Índice de Despesa com Saúde e Saneamento do município i; Idap = Índice de Despesa com Assistência Social e Previdência do município i; Idec = Índice de Despesa com Educação e Cultura do município i; IG= Índice de Gini no município i; IMF= Índice de Mortalidade Infantil do município $\mathrm{i}$; Idhm = Índice de Desenvolvimento Humano do Município i; $\mathrm{P}=$ Participação da Variável W do município i. 
Por fim, a dimensão ambiental representada pelo Indicador Parcial Ambiental (IAi), inclui variáveis que caracterizam a ação antrópica no meio ambiente e a qualidade de vida da população, conforme eq. 3 :

$$
I A i=(I S+I E F M+I P H+I A E+I A E B+I D D+I D E E+I D C L+I A V+I G R S) \times P
$$

Em que: $\mathrm{IAi}=$ Indicador Parcial Ambiental; IS= Índice da Produção de Silvicultura do município i; Iefm = Índice de Estabelecimentos com Matas do município i; IPH= Índice da Poluição Hídrica do município i; IAE= Índice de Abastecimento de Água Encanada no município i; Iaeb= Índice de Abastecimento de Água Encanada e Banheiro no município i; IDD= Índice de Densidade Demográfica dos domicílios no município i; Idee= Índice de Domić́lios com Energia Elétrica no município i; Idcl=Índice de Domicílios com Coleta de Lixo no município i; IAV=Índice de Área Verde por habitante no município i; Igrs=Índice de Geração de Resíduos Sólidos no município i; e $\mathrm{P}=$ Participação da variável $\mathrm{W}$ do município i.

Nas equações de 1 a 3, a participação "P" da variável "W" do município "i" foi calculado segundo a eq. 4 :

$$
P=W i \div \sum W i
$$
estado.

Em que: $\mathrm{Wi}=$ valor da variável para o município, e $\Sigma \mathrm{Wi}=$ corresponde ao valor total do

Os indicadores de cada município "IPWi" foram calculados com base nos parâmetros de normalização a seguir:

a) Se a variável influencia o indicador negativamente:

$$
I P W i=(W m a ́ x-W i) \div(W m a ́ x-W m i ́ n)
$$

b) Se a variável influencia o indicador positivamente:

c)

$$
I P W i=(W i-W m i ́ n) \div(W \operatorname{má} x-W m i ́ n)
$$

Em que: $\quad$ IPWi $=$ índice da variável $\mathrm{W}$ do município $\mathrm{i}$; $\mathrm{Wi}=$ valor da variável $\mathrm{W}$ no município i; Wmín = menor valor da variável no estado; Wmáx = maior valor da variável no estado.

A estimação do Indicador de Desenvolvimento Regional Sustentável (Idrs) para cada município é obtido de acordo com o exposto na eq. 7:

$$
\text { IDRSi }=(I E i \times 1 / 3)+(I S i \times 1 / 3)+(I A i \times 1 / 3)
$$

O Idrs estimado é categorizado em três estágios de desenvolvimento, conforme Bianco, Lima e Morejon (2016). Se o Idrs for maior ou igual a 0,050, considera-se estágio avançado de desenvolvimento, se o valor estiver entre 0,049 e 0,010 , estágio de transição e se for menor que 0,010 , esse estágio de desenvolvimento é considerado retardatário.

\section{RESULTADOS E DISCUSSÃO}

Esta seção apresenta, primeiramente, um panorama da indústria de celulose, em nível mundial e nacional, contextualizado à situação da microrregião Porto Seguro no setor; posteriormente, são descritos e discutidos os resultados acerca da estimação do Idrs e da análise do uso e ocupação do solo na microrregião estudada por meio do uso de mapas. 


\subsection{Panorama da indústria de celulose}

Os incentivos das políticas de desenvolvimento da indústria nacional que ocorreram a partir da segunda metade do século XX e a intensificação dos investimentos em infraestrutura, possibilitaram a expansão do setor de celulose no Brasil (Sperotto, 2014). Esses investimentos viabilizaram a instalação de agroindústrias e transferência de empresas, antes concentradas no Sudeste do país, para outras regiões como Nordeste e Centro-Oeste.

Essas duas últimas regiões foram escolhidas por condições edafoclimáticas (solo e clima), geomorfológicas, disponibilidade de recursos hídricos, terras a preços relativamente baixos fatores que tornaram possível para o setor atingir altos níveis de produtividade (Perpetua; Kröger; Thomaz Junior, 2017; Correa, 2014). Dados da Organização das Nações Unidas para a Agricultura e Alimentação (FAO, 2017), apontam o Brasil como principal produtor de eucalipto para fabricação de celulose e maior exportador do produto, tornando estratégico esse setor para a economia nacional. A indústria de celulose brasileira é concentrada, permitindo obter ganhos de escala, gerando vantagens competitivas associadas à disponibilidade de terras, mão de obra e condições de solo e clima favoráveis.

Quando se analisa o Brasil em termos de produtividade florestal, a partir do incremento médio anual (IMA), esse se mostra, também, superior aos principais países que atuam no setor florestal. Enquanto no Brasil, o IMA é $36 \mathrm{~m}^{3} / \mathrm{ha} / \mathrm{ano}$, nos Estados Unidos, Canadá e Rússia, importantes produtores, o IMA atinge apenas $10 \mathrm{~m}^{3} /$ ha/ano, e na Bahia, esse incremento está entre 25 a 43 m³/ha/ano (Associação Baiana das Empresas de Base Florestal - Abaf, 2019).

Dispondo dessas vantagens e de incentivos governamentais no âmbito federal e, posteriormente, estendido às esferas estadual e municipal, a indústria de celulose na Bahia expandese e é fortalecida a partir da década de 1990, atraindo empresas de transformação e passando a ganhar destaque em nível nacional e mundial. Os primeiros plantios de eucalipto iniciam-se pelo extremo sul baiano ao final da década de 1970, com a chegada de empresas madeireiras após a construção da BR-101, estendendo-se para o litoral norte do estado, que também se despontaria como um importante polo florestal (Perpetua; Kröger; Thomaz Junior, 2017).

O Espírito Santo, por exemplo, apesar de não ser o principal estado produtor de eucalipto, possui fatores relevantes no setor. A proximidade da indústria a rodovias e portos, atraiu importantes empresas para esse estado, levando-o à especialização na produção e exportação de celulose, favorecendo também sua expansão para municípios vizinhos em outros estados, como Minas Gerais, Bahia e, mais recentemente, no Rio de Janeiro (Fibria, 2019).

Em 2018, a produção de madeira de eucalipto no Brasil totalizou 4,2 bilhões de reais e as exportações de celulose ultrapassaram 8 bilhões de dólares. Aproximadamente $98 \%$ das divisas geradas com a produção de celulose no Brasil foram oriundas de oito estados produtores: Mato Grosso do Sul, Bahia, Espírito Santo, Maranhão, Rio Grande do Sul, Minas Gerais, São Paulo e Paraná. Porém, cerca de $40 \%$ desta produção concentra-se nos estados de Mato Grosso do Sul e Bahia, revelando a forte importância desses dois estados brasileiros nesse setor (IBÁ, 2019).

Outros estados estão há mais tempo no setor, com destaque para São Paulo e Minas Gerais, e nesse último existe produção desde o início da década de 1970, com importantes empresas atuando em mais de 50 municípios (Cenibra, 2019). Além disso, em 2014 o estado do Maranhão com apenas uma unidade industrial instalada, desponta nesse cenário como um dos principais produtores de madeira de eucalipto e exportadores de celulose do país (Suzano, 2017).

Além do eucalipto, nos estados do Rio Grande do Sul, São Paulo e Paraná, há cultivos de pinus, gênero mais adaptado ao clima e solo desses locais, especialmente do Sul do país. Nesses estados, apesar dos menores números absolutos do valor da produção de madeira e exportação de celulose em relação aos demais no ano de 2018, há maior número de fábricas de papel. Nesses estados, a integração entre as indústrias de celulose e de papel revela melhor desempenho na agregação de valor ao longo da cadeia produtiva e potencial para a formação de arranjos produtivos (IBÁ, 2019). 
Nesse contexto, o estado da Bahia se destaca como o segundo maior exportador de celulose do país, respondendo por quase $1 / 4$ de toda a madeira de eucalipto produzida nacionalmente em 2018. Todavia, a atividade florestal é concentrada em poucos municípios, conforme Tabela 1, localizados predominantemente no sul do estado, responsáveis por $83 \%$ de toda a produção estadual de madeira de eucalipto para celulose em 2018.

Tabela 1 - Produção de madeira de eucalipto para celulose nos principais municípios produtores da Bahia no ano de 2018

\begin{tabular}{lcc}
\hline Município & Quantidade $\left(\mathbf{m}^{\mathbf{3}}\right)$ & \% Bahia \\
\hline Caravelas & 2.376 .922 & 17,3 \\
Mucuri & 1.647 .432 & 12,0 \\
Nova Viçosa & 1.565 .829 & 11,4 \\
Alcobaça & 1.277 .700 & 9,3 \\
Santa Cruz Cabrália & 988.821 & 7,2 \\
Itanagra & 919.740 & 6,7 \\
Eunápolis & 826.230 & 6,0 \\
Belmonte & 734.207 & 5,3 \\
Porto Seguro & 727.422 & 5,3 \\
Itagimirim & 358.641 & 2,6 \\
Outros municípios baianos & 2.340 .124 & 17,0 \\
\hline Total da Bahia & 13.763 .068 & 100,00 \\
\hline
\end{tabular}

Fonte: Adaptada de "Pesquisas", do Sistema IBGE de Recuperação Automática (Sidra), 2018.

A indústria de celulose baiana é concentrada em dois polos: no sul do estado atuam as empresas Suzano Papel e Celulose S/A, sediadas no município de Mucuri, Veracel Celulose S/A em Eunápolis, abrangendo 22 municípios situados nas microrregiões Porto Seguro e Ilhéus/Itabuna. A celulose produzida por essas duas empresas é do tipo branqueada, para fabricação de papel para a indústria gráfica e de higiene pessoal.

Em 2017, houve a fusão das empresas Suzano e Fibria, fazendo com que o município de Mucuri passasse a ter a maior unidade de celulose do mundo. O segundo polo situa-se no litoral norte baiano, com a empresa Bracell, sediada em Camaçari, e operações florestais concentradas nas microrregiões Alagoinhas e Entre Rios. (Bracell, 2018; Suzano, 2019; Veracel, 2018).

O setor de celulose é relevante para a economia local e baiana na geração de divisas para Bahia e Brasil. Porém, muitas são as transformações na paisagem rural e urbana dos municípios que passaram a plantar eucalipto e abrigar as unidades industriais, com destaque para a microrregião Porto Seguro, responsável por mais da metade dos plantios florestais na Bahia (Abaf, 2019).

\subsection{Dinâmica de desenvolvimento, uso e cobertura do solo}

Os resultados acerca da dinâmica de uso do solo indicam que os cultivos de eucalipto na microrregião Porto Seguro ocorrem em municípios com diferentes graus de urbanização de forma mais desconcentrada nas áreas ao norte da região, se aglutinando à medida que avançam até o sul. $\mathrm{O}$ mapa da Figura 2 ilustra esta dinâmica, retratando o uso e cobertura do solo na microrregião Porto Seguro nos anos de 1985 e 2018. 


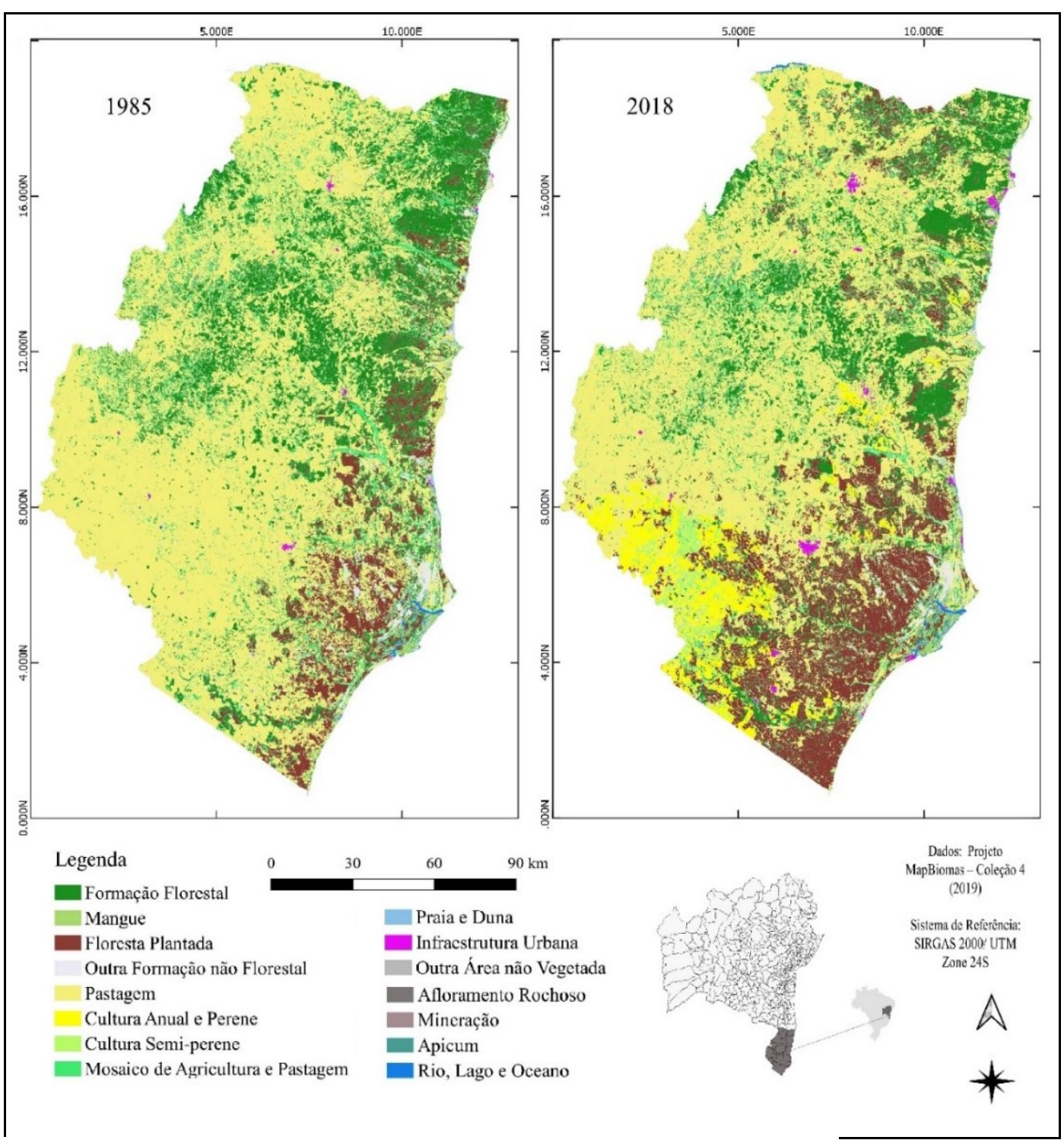

Figura 2 - Uso e cobertura do solo: microrregião Porto Seguro (1985 e 2018)

Fonte: Resultados da pesquisa

Em 1985, o território já possuía florestas plantadas, principalmente em áreas próximas ao litoral. Todavia, a tendência de ocupação se direcionou para o interior, principalmente após a implantação de importantes unidades de conservação, com destaque para os Parques Nacionais: Pau-Brasil, Alto do Cariri, Monte Pascoal e Descobrimento, além de Áreas de Proteção Ambiental e Reservas Extrativistas nas zonas litorâneas. Tais unidades têm sua importância tanto para o fortalecimento das instituições ambientais, quanto para a conscientização da sociedade em favor da preservação das áreas com florestas naturais e de práticas produtivas mais sustentáveis (Instituto do Meio Ambiente e Recursos Hídricos - Inema, 2019).

$\mathrm{Na}$ Tabela 2, observa-se que o cultivo de eucalipto, anteriormente concentrado nos municípios de Mucuri, Nova Viçosa, Caravelas, Prado e Alcobaça, avançou por toda a microrregião, espraiando-se para Porto Seguro, Eunápolis, Santa Cruz Cabrália e Itamaraju. A microrregião Porto Seguro abrange 2,7 milhões de hectares, dos quais 46\% são ocupados com pastagem, sendo que as áreas dedicadas à pecuária reduziram 18\% entre 1985 e 2018 (Tabela 2), assim como as áreas com florestas naturais, que diminuíram $21 \%$. 
Tabela 2 - Principais tipos de uso e área ocupada (hectares): microrregião Porto Seguro, Bahia, 1985 e 2018

\begin{tabular}{|c|c|c|c|c|}
\hline \multirow{2}{*}{ Tipos de uso } & \multicolumn{2}{|c|}{ Área ocupada (ha) } & \multirow{2}{*}{$\begin{array}{l}\text { \% Variação } \\
(\mathbf{b}-\mathbf{a})\end{array}$} & \multirow{2}{*}{$\begin{array}{c}\text { \% área total em } \\
2018\end{array}$} \\
\hline & 1985 (a) & 2018 (b) & & \\
\hline Floresta natural & 624.597 & 495.213 & -21 & 18 \\
\hline Floresta plantada & 210.235 & 459.303 & 119 & 17 \\
\hline Pastagem & 1.548 .381 & 1.272 .559 & -18 & 46 \\
\hline Mosaico (agropecuária) & 310.547 & 285.336 & -8 & 10 \\
\hline Agricultura & 0,6 & 198.947 & 33.394 .015 & 7 \\
\hline Corpos d'água & 6.658 & 8.733 & 31 & 0 \\
\hline Infraestrutura urbana & 3.301 & 12.494 & 278 & 0 \\
\hline Outros & 66.260 & 39.411 & 7 & 1 \\
\hline Total & 2.769 .979 & 2.771 .996 & 2.017 & 100 \\
\hline
\end{tabular}

Fonte: Resultados da pesquisa

As áreas com florestas plantadas expandiram-se (119\% entre 1985 e 2018) associadas à eucalitptocultura, abrangendo $17 \%$ de todo o território da microrregião. Ao mesmo tempo, a agricultura apresentou mudanças relevantes na região. Ocupava $11 \%$ da área total em 1985, apenas com os cultivos em mosaico; todavia, em meados da década de 1990, ocorre a expansão dos cultivos anuais, semiperenes e permanentes, com destaque para o mamão e a cana-de-açúcar, além de cultivos diversos de leguminosas, cereais, raízes e frutíferas, tanto para fins comerciais quanto para subsistência. Assim, no ano de 2018 as atividades agrícolas passaram a ocupar 17\% do solo da microrregião, atingindo 484.284 hectares quando somadas aos cultivos em mosaico (Mapbiomas, 2019).

Nesse contexto, vale destacar a expansão do cultivo de cana-de-açúcar, estimulado pela implantação de usina de álcool no município de Medeiros Neto. Já os cultivos de mamão foram ampliados por conta das operações de empresa exportadora em Mucuri (Bello Papaya, 2019; Usina Santa Maria, 2019). Nesse sentido, houve um processo de especialização produtiva na região, para além da indústria de celulose, envolvendo também outros setores do agronegócio.

Em síntese, as mudanças no uso e na cobertura do solo observadas nos anos de 1985 e 2018 na microrregião Porto Seguro são marcadas, principalmente, pelo predomínio das pastagens nas áreas mais interioranas e pelo avanço da eucaliptocultura nas zonas mais próximas ao litoral e em áreas anteriormente ocupadas com pastagem.

Em relação ao Indicador de Desenvolvimento Regional Sustentável (Idrs) estimado, a Tabela 3, a seguir, apresenta os municípios baianos com os melhores resultados. No âmbito estadual, o Idrs indica a presença de "ilhas" de desenvolvimento, com os melhores resultados para a região metropolitana de Salvador e os maiores centros urbanos do estado.

Tabela 3 - Indicadores parciais dos 10 municípios com maior Idrs na Bahia

\begin{tabular}{|c|c|c|c|c|c|c|c|c|c|}
\hline \multirow{2}{*}{ Municípios } & \multicolumn{4}{|c|}{1991} & \multicolumn{4}{|c|}{2010} & \multirow{2}{*}{$\begin{array}{c}\mathbf{b} / \mathbf{a} \\
\% \\
\end{array}$} \\
\hline & IE & IS & IA & IDRS (a) & IE & IS & IA & IDRS (b) & \\
\hline Salvador & 2,360 & 0,025 & 0,025 & 0,803 & 1,477 & 0,016 & 0,013 & 0,502 & $-37,5$ \\
\hline Camaçari & 0,111 & 0,016 & 0,027 & 0,051 & 0,136 & 0,014 & 0,028 & 0,059 & 16,1 \\
\hline Feira de Santana & 0,063 & 0,017 & 0,046 & 0,042 & 0,098 & 0,015 & 0,044 & 0,052 & 25,1 \\
\hline Eunápolis & 0,003 & 0,015 & 0,022 & 0,013 & 0,019 & 0,014 & 0,106 & 0,046 & 243,6 \\
\hline Lauro de Freitas & 0,035 & 0,022 & 0,022 & 0,026 & 0,089 & 0,019 & 0,024 & 0,044 & 68,9 \\
\hline Mucuri & 0,036 & 0,010 & 0,011 & 0,019 & 0,017 & 0,012 & 0,089 & 0,039 & 108,6 \\
\hline Caravelas & 0,003 & 0,012 & 0,037 & 0,017 & 0,005 & 0,010 & 0,097 & 0,038 & 117,7 \\
\hline Juazeiro & 0,030 & 0,014 & 0,032 & 0,025 & 0,030 & 0,013 & 0,054 & 0,033 & 28,5 \\
\hline Vitória da Conquista & 0,028 & 0,015 & 0,035 & 0,026 & 0,038 & 0,015 & 0,034 & 0,029 & 11,9 \\
\hline Cotegipe & 0,003 & 0,008 & 0,011 & 0,007 & 0,003 & 0,010 & 0,064 & 0,026 & 255,4 \\
\hline
\end{tabular}

Nota: IE = Indicador Parcial Econômico, IS = Indicador Parcial Social, IA = Indicador Parcial Ambiental, Idrs= Indicador de Desenvolvimento Regional Sustentável.

Fonte: Resultados da pesquisa 
Todavia, os resultados dos demais municípios baianos, permitem identificar nuances da dinâmica de desenvolvimento local. Nota-se que os municípios com melhor desempenho no Idrs se situam, em sua maioria, no estágio de transição, estando localizados nas microrregiões de Salvador e Porto Seguro (Tabela 3). Entretanto, comparando-se o Idrs de 1991 e 2010, Salvador registrou queda no ritmo de desenvolvimento $(-37,5 \%)$ em relação aos demais municípios, distintamente dos demais, especialmente de Eunápolis, Cotegipe, Caravelas e Mucuri.

Diferentemente de Cotegipe, que vem avançando na pecuária e turismo, a melhora nos outros três do Idrs pode ser relacionada, principalmente, ao setor de celulose, pois grande parte do território desses municípios é ocupado com plantios de eucalipto, os quais fazem parte da microrregião Porto Seguro. A Figura 3 ilustra os resultados do Idrs e indicadores parciais para essa microrregião.

Nessa microrregião, composta por 19 municípios, 18 abrigam maciços florestais para produção de celulose, sendo a região com maior presença do setor no estado da Bahia. Salienta-se, porém, que enquanto a tendência observada para a maioria dos municípios baianos foi de um maior Idrs associado ao indicador econômico, boa parte daqueles municípios apresentaram valor do Idrs mais associado à composição de variáveis ambientais (Figura 3).

A Figura 3 revela que na maioria dos municípios ocorreu melhora nos indicadores parciais e no Idrs, exceção para Medeiros Neto, Nova Viçosa e Lajedão. Nos municípios de Mucuri e Caravelas, o Indicador Ambiental (IA) afetou positivamente a melhora no Idrs e em Teixeira de Freitas e Porto Seguro o aumento esteve mais atrelado ao Indicador Econômico (IE). Dentre a microrregião de Porto Seguro, o município de Eunápolis foi o que apresentou a maior alteração entre 1991 e 2010 no Idrs (243\%), resultado dos efeitos positivos do IE (535\%) e IA (382\%).

Observando o Idrs, verifica-se que alguns municípios da microrregião analisada, sinalizaram forte dependência do setor de celulose. Em Mucuri, por exemplo, além das florestas plantadas, há também a maior unidade industrial do estado, a qual se constitui em importante condicionante das divisas locais, do emprego formal e, consequentemente, do dinamismo econômico do município. Mesmo assim, entre 1991 e 2010, o resultado econômico foi superado pelo Indicador Ambiental, que aumentou $721 \%$, o melhor desempenho dentre os 417 municípios baianos, sinalizando a consolidação do município na silvicultura (Figura 3). 


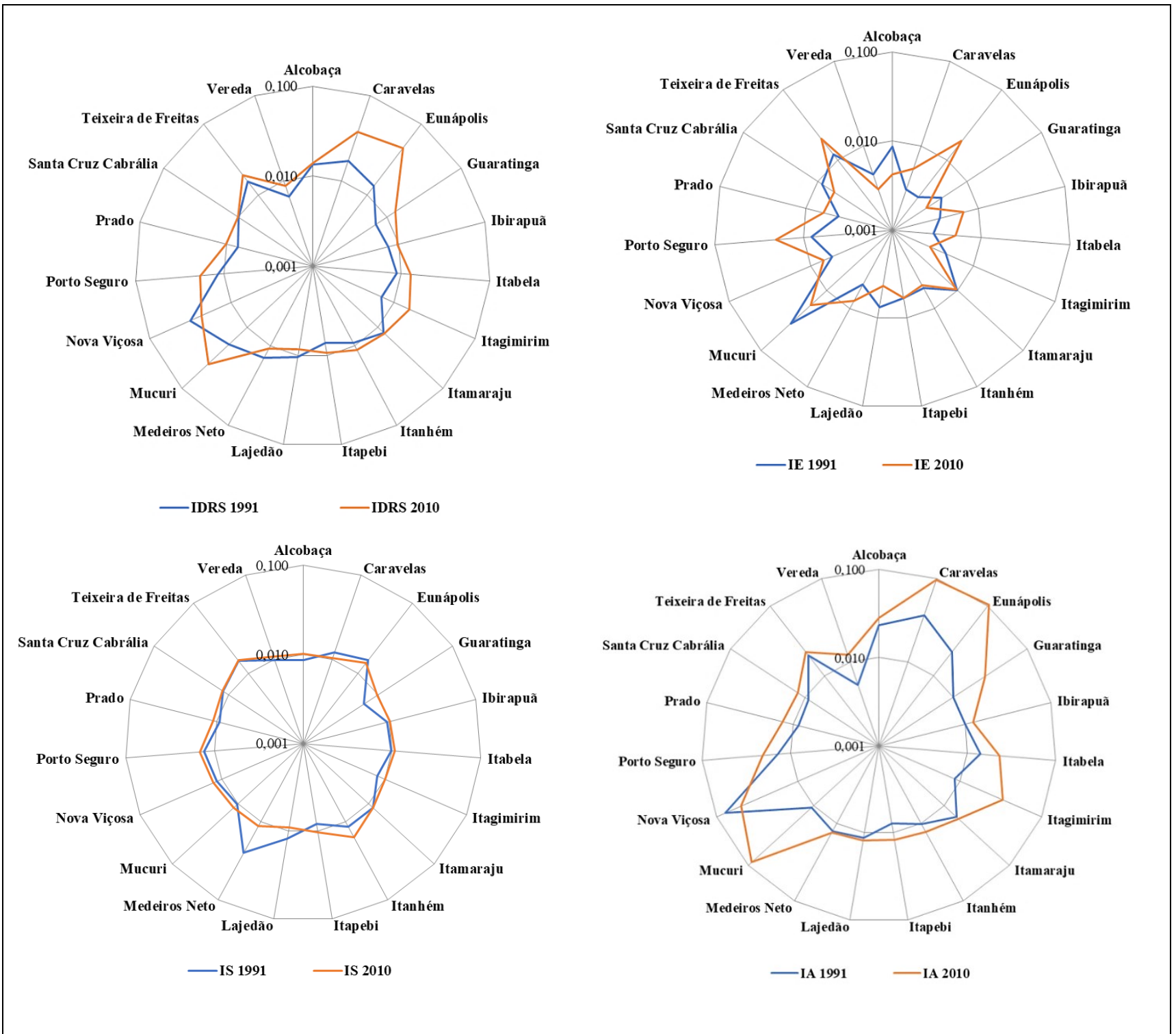

Figura 3 - Idrs e indicadores parciais IE, IS e IA para a Microrregião Porto Seguro e Bahia, 1991 e 2010

Nota: Idrs= Indicador de Desenvolvimento Regional Sustentável, IE = Indicador Parcial Econômico, IS = Indicador Parcial Social, IA = Indicador Parcial Ambiental.

Fonte: Resultados da pesquisa

No Indicador Social, a maior evolução foi de 37\% alcançada pelo município de Itanhém, pois houve a ampliação de despesa pública com saúde e assistência, resultando em aumento da frequência escolar e queda da mortalidade infantil. Por outro lado, Medeiros Neto foi o município que menos acompanhou os avanços sociais observados para os demais municípios, em relação às variáveis incluídas neste trabalho, registrando uma queda de 55\%. A situação do IS não evidenciou uma tendência estrita relacionada à indústria de celulose; a maioria dos municípios permaneceu no mesmo patamar ou variações associadas diretamente à disponibilidade de serviços públicos à população.

Apesar de relevante para a microrregião, o setor de celulose não se mostra um fator imperativo à dinâmica de desenvolvimento dos municípios produtores de eucalipto ou mesmo aqueles em seu entorno. O município de Jucuruçu, por exemplo, apesar de não possuir florestas plantadas, apresentou aumento de $20 \%$ no Idrs, associado à melhora nos Indicadores Ambiental (84\%) e Social (9,6\%), enquanto o Econômico apresentou queda de 36\%.

Ao analisar os resultados do Indicador de Desenvolvimento Regional Sustentável com o uso e cobertura do solo, observa-se que a dinâmica de desenvolvimento na microrregião, apresenta 
transformações influenciadas, conforme Lima e Simões (2010) salientam pelo número e tipo de empresas que nelas se instalam. Assim, Mucuri e Eunápolis, que abrigam grandes unidades industriais, se destacaram em relação ao demais municípios, revelando a importância do setor de celulose, que se consolidou como importante fator de geração de renda, êxodo rural e urbanização, pela atração de mão de obra, tornando a economia local fortemente atrelada às condições de evolução do setor.

Reunindo o maior número de municípios associados à indústria de celulose, com extensas áreas dedicadas ao cultivo de eucalipto, a dinâmica do desenvolvimento e cobertura do solo na microrregião Porto Seguro relaciona-se à eucaliptocultura, principalmente no que se refere ao Indicador Ambiental. De maneira geral, o Idrs na região apresentou melhorias entre os dois períodos analisados, com exceção de alguns municípios.

No entanto, é importante ressaltar que anteriormente à inserção do setor de celulose, o histórico de ocupação da região é marcado por algumas atividades, tais como o turismo, a pecuária e a agricultura, com destaque para o cacau (Almeida et al, 2008). Além disso, a considerável expansão das atividades agrícolas verificada neste estudo (Figura 2), associada principalmente ao crescimento do setor sucroalcooleiro e da produção de frutos na região, indica que a indústria de celulose, apesar de pujante, não deve ser considerada isoladamente como fator de impacto no desenvolvimento dos municípios, exceto no caso de Eunápolis e Mucuri, que apresentam um modelo produtivo mais influenciado pelo setor.

A expansão das atividades agrícolas diversas ao cultivo de eucalipto, assim como os resultados favoráveis do Indicador Parcial Ambiental na maioria dos municípios desafiam, em certa medida, a literatura no que diz respeito ao potencial de geração de impactos ambientais negativos, assim como a monopolização do território associados à atuação da indústria de celulose na região Melina (2013), Perpetua; Kröger; Thomaz Junior (2017), Perpetua e Thomaz Junior (2016). A concentração de terras e os problemas socioambientais relacionados às grandes indústrias integradas à produção no campo são intrínsecos às atividades que seguem a lógica de acumulação do atual modelo produtivo, conforme descrito em Silva (1998) e, portanto, não são fenômenos restritos ao setor de celulose.

No entanto, corroborando com as questões tratadas na literatura em relação à atuação do setor na região, verifica-se que o cultivo de eucalipto para produção de celulose revela fragilidades quanto ao aspecto da sustentabilidade, pois as florestas plantadas constituem-se em monocultura; ao mesmo tempo, a magnitude do capital associado à indústria de celulose, e a dependência desta aos fatores externos (comércio internacional, taxa de câmbio etc.) não indicam um desenvolvimento de caráter endógeno. Tal fato também é verificado ao se observar a pouca evolução no Indicador Parcial Social dos municípios, principalmente naqueles que abrigam unidades industriais.

De maneira geral, notam-se iniciativas de diversificação produtiva na região, as quais são favoráveis ao desenvolvimento em uma concepção de sustentabilidade. Ao se assumir um desenvolvimento de caráter endógeno, a riqueza gerada no modelo produtivista passaria a ampliar o escopo de concentração dos grandes grupos empresariais para uma prática mais acessível aos agricultores familiares e pequenos proprietários de terras, constituindo-se em uma oportunidade de geração e melhor distribuição de renda em nível local, favorecendo assim o desenvolvimento sustentável.

\section{CONSIDERAÇÕES FINAIS}

Nas últimas décadas, a Bahia se destaca no setor de celulose, o qual vem influenciando a dinâmica econômica, principalmente na microrregião Porto Seguro, pela presença de duas grandes unidades industriais e 18 municípios com extensas áreas dedicadas ao cultivo de eucalipto e operações industriais.

Em relação ao uso do solo, predominam as áreas de pastagens, as quais ocupavam a maior parte do território analisado, tanto em 1985 quanto em 2018 que, no entanto, têm cedido área para a

Revista de Gestão Social e Ambiental - RGSA, São Paulo, v. 14, n. 2, p. 65-81, maio/ago. 2020. 
eucaliptocultura. Apesar da forte presença da indústria de celulose e pecuária na microrregião Porto Seguro, observa-se a ocorrência de um processo de diversificação produtiva, especialmente nas atividades agrícolas. Outra importante mudança verificada em todo o território é a ampliação da infraestrutura urbana, reflexo do processo de urbanização verificado nas últimas décadas em nível nacional, associado à dinamização dos setores industrial e de serviços.

Apesar de não ser o único determinante do processo de desenvolvimento nos municípios analisados, verifica-se que a indústria de celulose relaciona-se com a dinâmica regional, constituindo-se em fator relevante na estimação do Indicador de Desenvolvimento Regional Sustentável, que na microrregião Porto Seguro revelou resultados acima da média para a maioria dos municípios.

Todavia, a presença de outras atividades agrícolas, pecuária e turismo, além dos diferentes níveis de atuação do setor de celulose em cada município analisado, podem também ter contribuído para o processo de desenvolvimento local. Uma relação mais direta do setor de celulose na dinâmica de desenvolvimento pode ser verificada de maneira mais expressiva nos municípios de Eunápolis e Mucuri, pela presença de duas grandes plantas industriais, além da predominância da eucaliptocultura nesses locais.

Sinteticamente, os Indicadores Parciais Ambiental e Econômico apresentaram os melhores resultados nos municípios em que a indústria de celulose é mais atuante. Já o desempenho do Indicador Social não sinalizou grandes avanços e se destacou nos municípios de menor densidade populacional, os quais estavam associados ao alcance das políticas sociais, permitindo implantar ou ampliar o acesso a serviços de saúde, educação e infraestrutura.

Ressalta-se que o Idrs, aplicado especificamente à análise da atuação do setor de celulose a nível municipal revelou limitações, pois, além da possibilidade dos períodos de estimação se restringir aos anos censitários, os resultados do Indicador Ambiental nos municípios da microrregião Porto Seguro têm maior relevância devido aos plantios de eucalipto, visto que, ao serem considerados como florestas plantadas, figuram como fator positivo no cálculo dos índices de área verde por habitante, estabelecimentos com matas e valor da produção na silvicultura. Todavia, tais limitações não invalidam a análise, haja vista que, além dos diversos índices adotados na estimação reduzirem o risco de enviesar os Indicadores Parciais e o Idrs, há a possibilidade, no caso de futuros estudos, de adequar os tipos de variáveis para cada índice e a periodicidade, a depender do nível de desagregação que se deseja analisar.

Por fim, as disparidades observadas neste estudo sinalizam um processo de desenvolvimento que necessita ampliar a sustentabilidade em direção à dimensão social, no sentido de promover maior autonomia e melhor qualidade de vida à população local, reduzindo a dependência econômica à indústria de celulose e aprimorando as medidas de política de acesso a serviços públicos básicos.

\section{REFERÊNCIAS}

Almeida, T. M. de. (2009). Cultivo de eucalipto no extremo sul da Bahia: modificações no uso da terra e socioeconômicas. Dissertação (Mestrado). 132. Programa de Pós-graduação em Desenvolvimento e Meio Ambiente, Universidade Estadual de Santa Cruz.

Almeida, T. M., dos Santos Moreau, A. M. S., \& Moreau, M. S. (2008). Reorganização socioeconômica no extremo sul da Bahia decorrente da introdução da cultura do eucalipto. Sociedade \& Natureza, 20(2).

Alves, L. R. A.; Lima, J. F. de. (2007) Desenvolvimento sustentável: elementos conceituais e apontamentos para reflexão. Integração. Ano XII(50).

Andrade, M. L. de.; Oliveira, G. G. de.(2016) A monocultura do eucalipto na Bahia: um retrato da apropriação privada da natureza e de conflitos sócio ambientais. Cadernos do Ceas: Revista crítica de humanidades, Salvador, (237), 294-326.

Revista de Gestão Social e Ambiental - RGSA, São Paulo, v. 14, n. 2, p. 65-81, maio/ago. 2020. 
Amaral Filho, J. do. (2011). A endogenização no desenvolvimento econômico regional e local. Planejamento e políticas públicas, (23), 261-286, jun.

Associação Baiana das Empresas de Base Florestal (Abaf). (2019). Bahia florestal: relatório 2019. Disponível em < http://www.abaf.org.br/wp-content/uploads/2019/08/BahiaFlorestal_ABAF_2019.pdf $>$ Acesso em 15 fev. 2020.

Associação da Indústria Brasileira de Árvores (IBÁ). (2018). Relatório Anual 2018. Disponível em $<$ https://www.iba.org/publicacoes $>$ Acesso em: 8 jun. 2019.

Associação da Indústria Brasileira de Árvores (IBÁ). (2019). Relatório Anual 2019. Disponível em $<$ https://www.iba.org/publicacoes> Acesso em: 10 jan. 2020.

Base de Dados do Instituto de Pesquisa Econômica Aplicada (Ipeadata). (2018). Dados regionais. Disponível em: $<$ http://www.ipeadata.gov.br/Default.aspx> Acesso em: 10 out. 2018.

Bellingieri, J. C. (2017). Teorias do desenvolvimento regional e local: uma revisão bibliográfica. RDE-Revista de Desenvolvimento Econômico, 2(37).

Belo Fruit (Empresa). (2019). Operações. Disponível em: < https://bellopapaya.com.br $>$ Acesso em: 15 nov 2019.

Bianco, T. S.; Lima, J. F. de.; Morejon, C. F. M. (2016). O Indicador de Desenvolvimento Regional Sustentável na Região Sul do Brasil. Revista do Desenvolvimento Regional, Santa Cruz do Sul, $21(2), 8-28$.

Bracell (Empresa). (2018) Operações. Disponível em: <https://www.bracell.com> Acesso em: 10 nov 2018.

Cenibra (Empresa). (2019). Perfil. Disponível em: <https://www.cenibra.com.br/empresa/> . Acesso em: 20 mar 2019.

Correa, D. V. G. (2014). Celulose: logística e distribuição internacional. Senai Editora, São Paulo.

Diegues, A. C. S. (1992). Desenvolvimento sustentável ou cidades sustentáveis: da crítica dos modelos aos novos paradigmas. São Paulo em Perspectiva, 22-29. jan/jun.

Furtado, C. (2004). Os desafios da nova geração. Revista de Economia Política, 24(4).

Fibria (Empresa). (2019). Relações com investidores. Disponível em:

$<$ https://ri.fibria.com.br/fibria/quem-somos>.Acesso em: 20 mar 2019.

Food and Agriculture Organization (FAO). (2017) Yearbook - Forest Products. 2017. Disponível em <https://ec.europa.eu/knowledge4policy/publication/fao-yearbook-forest-products-2017_en> Acesso em: 13 set. 2019.

Graziano Neto, F. (1986). Questão Agrária e Ecologia - Crítica da moderna agricultura. (3 ed.) São Paulo, Brasiliense.

Instituto Brasileiro de Geografia e Estatística. (1990) Mesorregiões e microrregiões do Brasil. (Ibge - Dgeo/Diter). Disponível em: <http://www.ngb.ibge.gov.br/Default.aspx?pagina=divisao $>$ Acesso em 30 maio 2019.

Instituto de Meio Ambiente e Recursos Hídricos (Inema). (2019). Unidades de Conservação. Disponível em: <http://www.inema.ba.gov.br/gestao-2/unidades-de-conservacao/> Acesso em: 28 $\operatorname{dez} 2019$.

Instituto Brasileiro de Geografia e Estatística (Ibge). (2018) Mapas temáticos. Disponível em:< https://mapas.ibge.gov.br/tematicos.html> Acesso em: 12 mar. 2018.

Revista de Gestão Social e Ambiental - RGSA, São Paulo, v. 14, n. 2, p. 65-81, maio/ago. 2020. 
Instituto de Pesquisa Econômica Aplicada (Ipeadata). (2018) Base de dados regionais. Disponível em: $<$ http://www.ipeadata.gov.br/Default.aspx > Acesso em: 21 jul. 2018.

Lima, A. C. D. C., \& Simões, R. F. (2010). Teorias clássicas do desenvolvimento regional e suas implicações de política econômica: o caso do Brasil. RDE-Revista de Desenvolvimento Econômico, 12(21).

Lima, A. E. M. A teoria do desenvolvimento regional e o papel do Estado. (2006) Análise Econômica, 24(45).

Lima, J. F. de., Alves, L. R., de Cezaro Eberhardt, P. H., \& Del Bianco, T. S.

(2011). Mensurar as desigualdades regionais no Brasil: proposta metodológica. Seminário

Internacional sobre Desenvolvimento Regional, 5. Santa Cruz do Sul, RS, Brasil, 17 a 19 de agosto de 2011.

Ministério da Indústria, Comércio Exterior e Serviços. (2019). Estatísticas de comércio exterior (Mdic). Disponível em: <http://comexstat.mdic.gov.br/pt/geral> Acesso em: 10 set. 2019.

Melina, L. L. (2013). A territorialização do monopólio no setor celulístico-papeleiro: a atuação da Veracel Celulose no Extremo Sul da Bahia (Doctoral dissertation, Universidade de São Paulo).

Oliveira, A. B., Pereira, J. M., \& Nascimento, A. A. (2018). Cadeia produtiva de papel e celulose e transformações recentes no sudoeste maranhense. InterEspaço: Revista de Geografia e

Interdisciplinaridade, 4(12), 135-154.

Perpetua, G. M.; Kröger, M.\& Thomaz Junior, A. (2017). Estratégias de territorialização das corporações agroextrativistas na América Latina: o caso da indústria de celulose no brasil. Revista Nera, 40, 61-87, set/dez.

Perpetua, G. M.; Thomaz Junior, A. (2016). Revisitando o conceito de acumulação do capital: a pilhagem territorial promovida pela Veracel Celulose no Extremo Sul da Bahia. Campo-território: Revista de Geografia Agrária. Edição especial, 225-256, jun.

Programa das Nações Unidas para o Desenvolvimento (Pnud). (2018). Atlas do Desenvolvimento Humano no Brasil. Indicadores. Disponível em<http://www.atlasbrasil.org.br/2013/pt/consulta/> Acesso em: 6 nov. 2018.

Projeto Mapbiomas. (2019). Série anual de mapas de cobertura e uso de solo do Brasil.

Disponível em:< http://mapbiomas.org/> Acesso em 10 jul 2019.

Relação Anual de Informações Sociais (Rais). (2018). Admissões desligamentos. Disponível em $<$ http://pdet.mte.gov.br/acesso-online-as-bases-de-dados $>$ Acesso em 30 out 2018.

Rodrigues, K.F.; Lima, J. F. de. (2013). Índice de desenvolvimento regional sustentável: uma análise das mesorregiões do Estado do Paraná no período de 2002 a 2008. Revista Geografar, Curitiba, 8(1), 175-202.

Sen, A. K. (2007) Desenvolvimento como liberdade. Editora Companhia das Letras.

Sistema Ibge de Recuperação Automática. (2018). Pesquisas. Disponível

em: $<$ https://sidra.ibge.gov.br/home/cnt/brasil> Acesso em: 5 nov 2018.

Sperotto, F. Q. (2014). A expansão do setor de celulose de mercado no Brasil: condicionantes e perspectivas. Indicadores Econômicos FEE, 41(4), 85-100.

Superintendência de Estudos Econômicos e Sociais da Bahia (SEI). (2018) Sistema de

Informações Municipais. Disponível em:

$<$ https://www.sei.ba.gov.br/index.php?option=com_wrapper\&view=wrapper\&Itemid=266 $>$ Acesso em: 15 nov. 2018. 
Superintendência de Estudos Econômicos e Sociais da Bahia (SEI). (2018) Mapas. Disponível em: $<$ https://www.sei.ba.gov.br/index.php?option=com_content\&view=article\&id=1856\&Itemid=496 > Acesso em: 15 nov. 2018.

Superintendência de Estudos Econômicos e Sociais da Bahia (SEI). (2018). Cartografia Temática. Relevo (1983), Tipologia climática (1998), Solos (2001) e Biomas (2004) Disponível em:

$<$ https://www.sei.ba.gov.br/index.php?option=com_content\&view $=$ article\&id=2612\&Itemid=611 $>$ Acesso em: 15 nov. 2018.

Suzano Papel e Celulose (Empresa). (2017). Relatório de sustentabilidade 2017. Disponível em: $<$ http://www.suzano.com.br/suzano/comunicacao/publicacoes/> . Acesso em: 19 jun. 2018.

Suzano Papel e Celulose (Empresa). (2019). História. Disponível em:

$<$ https://www.suzano.com.br/a-suzano/historia/> Acesso em: 19 jun. 2019.

Usina Santa Maria (Empresa). (2019) Institucional. Disponível em:

$<$ http://www.usinasantamaria.com.br/site/index.php/institucional/> Acesso em: 15 nov 2019.

Veracel Celulose (Empresa). (2018). Operações. Disponível em:

$<$ http://www.veracel.com.br/nossas-operacoes/> Acesso em: 20 abr. 2018. 